\title{
BILATERAL BLINDNESS DUE TO ANTI-TUBERCULAR TREATMENT: A RARE PRESENTATION
}

\section{SULATHA V BHANDARY ${ }^{1}$, AKSHAY SEHGAL ${ }^{1 *}$, LAVANYA G RAO ${ }^{2}$, KRISHNA RAO A ${ }^{1}$, PALLAK KUSUMGAR ${ }^{1}$, HARISH THANUSUBRAMANIAN ${ }^{3}$}

${ }^{1}$ Department of Ophthalmology, Kasturba Medical College, Manipal University, Manipal - 576 104, Karnataka, India. ${ }^{2}$ Department of Ophthalmology, Srinivas Institute of Medical Sciences and Research Centre, RGUHS, Mangalore - 575 021, Karnataka, India. ${ }^{3}$ Department of Pharmacology, Kasturba Medical College, Manipal University, Manipal - 576 104, Karnataka, India. Email: akshaysehgal08@gmail.com

Received: 21 March 2016, Revised and Accepted: 05 April 2016

\section{ABSTRACT}

Ethambutol and isoniazid (INH) are antimicrobial agents used in the treatment of tuberculosis. Optic neuropathy is a well-recognized toxic effect of these drugs, usually manifesting as a decrease in visual acuity and deficits in color vision. This study presents the case of a 75-year-old male diagnosed of spinal tuberculosis, who developed irreversible bilateral optic neuropathy causing complete blindness induced by ethambutol and INH. Ophthalmologic examination revealed sluggish pupillary reactions and optic disc pallor in both eyes. Visual evoked potential and magnetic resonance imaging brain complemented the confirmation of the diagnosis.

Keywords: Ethambutol, Isoniazid, Optic neuritis, Tuberculosis.

(C) 2016 The Authors. Published by Innovare Academic Sciences Pvt Ltd. This is an open access article under the CC BY license (http://creativecommons. org/licenses/by/4. 0/) DOI: http://dx.doi.org/10.22159/ajpcr.2016.v9s2.11823

\section{INTRODUCTION}

Tuberculosis is the most common cause of infectious disease-related mortality worldwide [1]. Ethambutol and isoniazid (INH) are synthetic first-line agents of the anti-tubercular treatment (ATT) against Mycobacterium tuberculosis. Ethambutol optic neuropathy is a wellrecognized adverse ocular event in patients who receive the drug for the treatment of mycobacterial infections [2]. However, most cases in literature are reversible [3]. Optic nerve involvement is a rare sideeffect of INH [4]. We, hereby, report a very rare event of bilateral total blindness due to ATT.

\section{CASE REPORT}

A 75-year-old man presented with a sudden decrease in vision in both eyes since 8 days which progressed to an inability to recognize faces. Over 8 days, vision loss progressed to no perception of light in both eyes. He had been on ATT for tuberculosis of spine for 3 months after which he developed ATT-induced hepatitis for which ATT was temporarily withdrawn. After 1 week, ethambutol, INH, streptomycin, and levofloxacin were re-started (but not pyrazinamide and rifampin due to their hepatotoxic side-effects). Following this, ATT was continued for 2 more months and then it was stopped again once the patient developed optic neuropathy.

His visual acuity was the absence of perception of light in both eyes. Examination of both eyes revealed ill-sustained pupillary reactions to light. Intraocular pressure in both eyes was normal. On fundus examination (Fig.1), an optic disc of both eyes had diffuse pallor, more on the temporal side with clear margins suggestive of primary optic atrophy. Visual evoked potential (VEP) showed the absence of waveforms in both eyes, confirming optic nerve pathology. Magnetic resonance imaging (MRI) brain showed hyperintensity of T2 flair with opticochiasmatic arachnoiditis.

ATT was discontinued and the patient was started on intramuscular injections of vitamin B1 $500 \mathrm{mg}$, vitamin B6 $25 \mathrm{mg}$, and vitamin B12 $0.5 \mathrm{mg}$ for 1 week. This was followed by oral supplementation of vitamins. He was also started on intravenous high-dose methylprednisolone $500 \mathrm{mg}$ twice daily for 5 days followed by oral steroids $(1 \mathrm{mg} / \mathrm{kg}$ ) for the next 11 days. The dose of oral steroids was

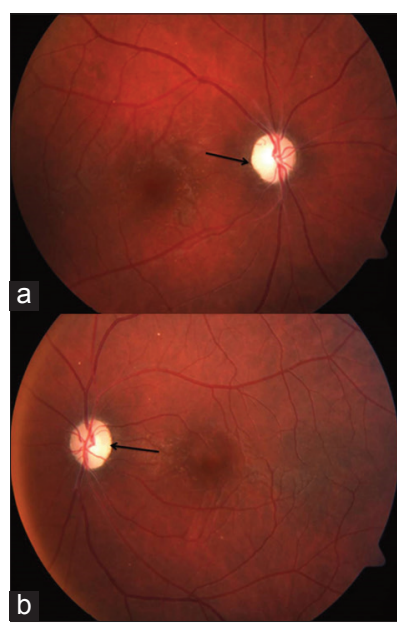

Fig. 1: Fundus photo of, (a) right eye, (b) left eye showing diffuse optic disc pallor, more prominent on the temporal side (arrow)

then gradually tapered off. At the time of discharge, vision was still no perception of light, and the optic disc was pale in both eyes. On follow-up visits at 1 and 3 months, there was no improvement in the vision noted.

\section{DISCUSSION}

Visual loss due to optic neuropathy is a rare side-effect of ATT particularly ethambutol and INH [5]. Although INH may also be responsible, ethambutol-associated optic neuropathy is more widely recognized [6]. Typical signs of ATT-induced optic neuritis include sudden onset vision loss, sluggish pupils, and pallor of the optic disc. MRI and VEP complement the confirmation of the diagnosis. However, the most cases documented in literature are reversible with pyridoxine, steroids and stoppage of ATT [4]. Moreover, such severe bilateral irreversible loss of vision is very rarely seen. Hence, clinicians should be well aware of the occurrence of such reactions to ATT. All patients on ATT should undergo regular ophthalmological evaluation before and during the course of treatment. 


\section{REFERENCES}

1. Starke JR, Munoz FM. Tuberculosis. In: Behrman RE, Kliegman RM, Jenson HB, Stanton FB, editors. Nelson Textbook of Pediatrics. $18^{\text {th }}$ ed Philadelphia, PA: WB Saunders; 2008. p. 1240-54.

2. Fraunfelder FW, Sadun AA, Wood T. Update on ethambutol optic neuropathy. Expert Opin Drug Saf 2006;5(5):615-8.

3. Fang JT, Chen YC, Chang MY. Ethambutol-induced optic neuritis in patients with end stage renal disease on hemodialysis: Two case reports and literature review. Ren Fail 2004;26(2):189-93.

4. Kulkarni HS, Keskar VS, Bavdekar SB, Gabhale Y. Bilateral optic neuritis due to isoniazid (INH). Indian Pediatr 2010;47(6):533-5.

5. Rodríguez-Marco NA Solanas-Alava S, Ascaso FJ, Martínez- Martínez L, Rubio-Obanos MT, Andonegui-Navarro J. Severe and reversible optic neuropathy by ethambutol and isoniazid An Sist Sanit Navar 2014;37(2):287-91.

6. Lim SA. Ethambutol-associated optic neuropathy. Ann Acad Med Singapore 2006;35(4):274-8. 